\title{
Immediate effects of a rhino-pharyngeal clearance protocol in nasal obstruction and middle ear condition of children under 3 years of age with upper respiratory infections: A randomized controlled trial
}

\author{
Ana Silva Alexandrino ${ }^{\mathrm{a}, \mathrm{b}, *}$, Rita Santos ${ }^{\mathrm{a}, \mathrm{b}}$, Cristina Melo ${ }^{\mathrm{a}, \mathrm{b}}$, David Tomé ${ }^{\mathrm{b}, \mathrm{c}}$, \\ José Mesquita Bastos ${ }^{\mathrm{d}}$, Guy Postiaux ${ }^{\mathrm{e}}$ \\ a Department of Physiotherapy, School of Health - P.Porto, Portugal \\ ${ }^{\mathrm{b}}$ Rua Dr. António Bernardino de Almeida, 400, 4200-072 Porto, Portugal \\ c Department of Audiology, School of Health -P.Porto, Portugal \\ d Baixo Vouga Hospital Centre, Aveiro, Portugal \\ e Department of Intensive Care and Pediatric Service, Grand Hôpital de Charleroi -GHDC, Charleroi, Belgium
}

\author{
KEYWORDS \\ Rhinopharyngeal \\ clearance; \\ Nasal irrigation; \\ Respiratory tract \\ infections; \\ Tympanometry; \\ Children; \\ Respiratory \\ physiotherapy
}

\begin{abstract}
Introduction and objectives: Children up to 2 years old are at high risk of respiratory infections and nasal irrigation is often prescribed. Yet, to date there is no sufficient knowledge about its immediate effects on the nasopharynx and middle ear. Therefore, this study aimed to analyze the effect of a rhino-pharyngeal clearance intervention protocol on nasal obstruction and middle ear condition in children under 3 years of age with URTI.

Materials and methods: Randomized controlled trial in a day-care centre of Porto, including 44 children randomized to Intervention Group (IG) and Control Group (CG). Nasal auscultation and tympanometry were performed at baseline (MO) as well as after the intervention (M1), which consisted of nasal irrigation $(\mathrm{NaCl} .9 \%)$ followed by a forced nasal inspiration in the IG, and after 30 min of normal activities, in the CG.

Results: In M1 there was a lower frequency of children classified as having an obstructed nasal sound in the IG when compared to the CG $(I G=33.3 \%$; CG $=68.4 \% ; p=0.042)$. We also observed an improvement of mean peak pressure (PP) in the IG (Left ear: $M 0=-124 \mathrm{daPa}$; $M 1=-92 \mathrm{daPa}$; $p=0.022$. Right ear: $M 0=-102 \mathrm{daPa} ; M 1=-77 \mathrm{daPa} ; p=0.021)$, which was not observed in the CG (Left ear: $M 0=-105 \mathrm{daPa} ; M 1=-115 \mathrm{daPa} ; p=0.485$. Right ear: $M 0=-105 \mathrm{daPa} ; M 1=-131 \mathrm{daPa}$; $p=0.105)$. There were no significant results concerning the compliance of the tympanic membrane.

Conclusions: The rhino-pharyngeal clearance improved the nasal obstruction and PP of the middle ear of children under 3 years of age with URTI.
\end{abstract}




\author{
PALABRAS CLAVE \\ Aclaramiento de la \\ rinofaringe; \\ Irrigación nasal; \\ Infecciones del tracto \\ respiratorio; \\ Timpanometría; \\ Niños; \\ Fisioterapia \\ respiratoria
}

\begin{abstract}
Efectos inmediatos de un protocolo de aclaramiento rinofaríngeo en la obstrucción nasal y el estado del oído medio en niños menores de 3 años con infecciones respiratorias superiores: un ensayo controlado aleatorizado
\end{abstract}

\begin{abstract}
Resumen
Introducción y objetivos: Los niños corren un alto riesgo de infecciones respiratorias superiores (IRS) y con frecuencia se prescriben irrigaciones nasales. Hasta hoy no hay suficiente conocimiento sobre sus efectos inmediatos en la nasofaringe y el oído medio. Por lo tanto, este estudio tuvo como objetivo analizar el efecto de un protocolo de intervención de limpieza nasal en la obstrucción y en el estado del oído medio de niños menores de 3 años con IRS.

Material y métodos: Ensayo controlado aleatorizado en una guardería de Oporto, incluidos 44 niños asignados al Grupo de intervención (IG) y al Grupo de control (CG). La auscultación nasal y la timpanometría se realizaron al inicio (M0) y después de la intervención (M1), que consistió en irrigación nasal ( $\mathrm{NaCl}$ 0,9\%) seguido de una inspiración nasal forzada en IG, y después de 30 min de actividades normales en CG.

Resultados: En M1 hubo una menor frecuencia de niños clasificados como con un sonido nasal obstruido en IG en comparación con CG (IG =33,3\%; CG =68,4\%; $p=0,042)$. También se observó una mejora de la presión máxima media (PP) en IG (oído izquierdo: $M 0=-124 \mathrm{daPa}$; $M 1=-92 \mathrm{daPa} ; \mathrm{p}=0,022$; oído derecho: $M 0=-102 \mathrm{daPa} ; M 1=-77 \mathrm{daPa} ; \mathrm{p}=0,021$ ), que no se observó en CG (oído izquierdo: $M 0=-105 \mathrm{daPa} ; M 1=-115 \mathrm{daPa} p=0,485$; oído derecho: $M 0=-105 \mathrm{daPa} ; M 1=-131 \mathrm{daPa} ; \mathrm{p}=0,105)$. No hubo resultados significativos con respecto al cumplimiento de la membrana timpánica.

Conclusiones: La limpieza nasal mejoró la obstrucción y la PP del oído medio de niños menores de 3 a nos con IRS.
\end{abstract}

\section{Introduction}

Acute respiratory infections (ARI) are the most frequent illnesses in childhood. ${ }^{1}$ Intense exposure to viral respiratory infections and a not-fully mature respiratory and immune system may be the cause why children are a major risk group. ${ }^{1}$ Furthermore, it is commonly accepted that day-care attendance has a substantial negative influence on children's health, as they are more exposed to ARI than children who stay at home. ${ }^{2}$

The most common signs and symptoms of URTI are nasal discharge, cough and nasal congestion, as well as signs of middle ear impairment. ${ }^{3,4}$ Most of URTI symptoms last for 7 days, although cough and runny nose can continue for up to 2-4 weeks. ${ }^{3,4}$ This creates a great burden for young children, since they breathe mainly through the nose, and the inability to remove nasal secretion by nose blowing can make breathing difficult for the child, leading to disturbed sleep, increased risk of obstructive apnoea and feeding difficulty. ${ }^{5}$

There is no evidence of an effective pharmacological treatment of URTI in children, since antibiotics are not recommended, neither narcotics, antihistamines or decongestants. ${ }^{6}$ So, an effective rhino-pharyngeal clearance may reduce or eliminate nasal secretions, re-establishing nasal breathing and preventing dissemination. ${ }^{7-10}$ There is also some other benefits reported, such as faster resolution of nasal symptoms during acute illness, mainly daytime rhinorrhoea and nocturnal nasal congestion, which may be responsible for a common use of nasal irrigation in young children. ${ }^{11,12}$

Nevertheless, not much is known about the immediate and direct impact of nasal irrigation in the nasopharynx and middle ear of children with URTI.

This study aimed to assess the effect of a rhinopharyngeal clearance intervention protocol in the nasal obstruction and middle ear condition of children up to 3 years of age with URTI attending day-care centres.

\section{Material and methods}

A randomized controlled trial was conducted (following CONSORT Statement) during a winter period (January to March, 2016) in seven private day-care centres in Porto. 
Ethical approval was obtained from the Ethics Committee of the School of Allied Health Technologies, Polytechnic Institute of Porto (CE_1744/2014).

After the Ethical approval, caregivers were contacted and informed about the aims and procedures of the study, after which they expressed a formal written consent in accordance with the Declaration of Helsinki. The children's caregivers were asked to fill in a registration form in order to collect sociodemographic characteristics, anthropometric data and risk profile history.

Inclusion criteria were defined as: children up to 3 years of age, both genders, with acute URTI (common cold, acute rhinosinusitis, pharyngitis or tonsillitis) in the first day of onset, reported by caregivers, along with the presence of rhinorrhoea at the initial assessment (MO). Exclusion criteria were defined as: preterm birth ( $<37$ weeks gestation), children with neuromuscular or chronic cardiopulmonary diseases (including respiratory allergies), children who have undergone ear, nose or throat surgery or with a history of grommets. Children were also excluded from this study if at MO they presented signs of lower respiratory tract impairment detected by pulmonary auscultation, or obstructive ear wax detected by otoscopy, as well as if they presented a normal respiratory health condition (Paediatric Respiratory Severity Score (PRSS) equal to 8) or a severe respiratory health condition (PRSS equal or above 16).

All children were submitted to a standard assessment protocol consisting of otoscopy followed by tympanometry, measured by a blinded audiologist, and pulmonary/nasal auscultation performed by a blinded respiratory physiotherapist. Children were seated on their caregiver's lap, and their head was sustained against the caregiver's chest.

\section{Instruments}

A handheld Impedance Audiometer MT10 (Interacoustics ${ }^{\circledR}$ USA), calibrated on 22 November 2010, according to the Food and Drug Administration requirements, with a $226 \mathrm{~Hz}$ probe tone, was used to assess the middle-ear condition of children (peak pressure of the middle-ear and compliance of the tympanic membrane).

Paediatric Respiratory Severity Score (PRSS) was used in order to assess children's baseline respiratory health condition, regarding subjective parameters (cough, nutrition, fever and rhinorrhoea) and objective parameters (dyspnoea, respiratory lung sounds, adventitious lung sounds and sputum). The final score is comprised in three categories: normal respiratory health condition $(P R S S=8)$, moderate impairment of the respiratory health condition $(8<$ PRSS $<16)$ and severe impairment of the respiratory health condition (PRSS > 16). PRSS obtained excellent values of content validity (Cronbach's $\alpha=0.80$ ) and test-retest reliability $($ ICC $2.1=0.91) .^{13}$

For nasal auscultation it was used a Littmann 3200 Electronic Stethoscope (3M Health Care ${ }^{\circledR}$, USA). Nasal auscultation sounds were collected within a $5 \mathrm{~cm}$ distance between the nose and the stethoscope diaphragm in an upright position in relation to the nostrils. Each sound was recorded in a digital format for $15 \mathrm{~s}$ using the software Zargis $^{\circledR}$ StethAssist ${ }^{T M}$. After being recorded, the nasal sounds were transferred to a laptop computer via
Bluetooth. Then, all sounds were coded and randomized by an independent and blinded investigator in regard to the study objectives. Coded nasal sounds were analyzed by an expert panel (three blinded respiratory physiotherapists with at least 3 years of experience in the treatment of children's nasopharyngeal obstruction), who classified the nasal sounds as "obstructed" and "non-obstructed." In a previous study, nasal auscultation revealed a substantial inter-rater $(K=0.75)$ and intra-rater $(K=0.69 ; K=0.61$ and $K=0.72$ ) reliability, in children. ${ }^{14}$

\section{Intervention protocol}

Children from Intervention Group (IG) underwent a standard intervention protocol performed by another respiratory physiotherapist, consisting on nasal irrigation with a isotonic saline solution (Physiological Serum - $0.9 \% \mathrm{NaCl}$ ), using a low pressure device (syringe-type or unidose) with no more than $50 \mathrm{ml}$. The child was seated on the physiotherapist's lap with the head slightly bended forward and rotated towards the side of the nostril to be cleaned. The serum was applied in the upper nostril and exited the lower nostril, carrying along nasal secretions. The same procedure was repeated as many times as necessary to successfully remove the nasal secretions from both nostrils and ensuring that the anterior region of the nasopharynx was unobstructed.

Then a sudden and profound nasal inspiration was triggered by briefly closing the child's mouth after a prolonged expiration, in order to assure the complete clearance of the posterior region of the nasopharynx. This manoeuvre was adapted from a respiratory physiotherapy technique named Désobstruction Rhinopharyngée Rétrograde (DRR), which is based on the Hering-Breuer deflation reflex and on the active inspiratory effort induced by pulmonary deflation. ${ }^{15,16}$

Children from Control Group (CG) continued their normal activities during the estimated time of the intervention protocol (about $30 \mathrm{~min}$ ).

The standard assessment was repeated after the intervention protocol in IG and after 30 min in CG (M1).

\section{Sample size}

Pilot testing in a sample with 10 children with URTI, with a mean age of $17.3 \pm 5.44$ months, $60 \%$ male gender, showed an effect size of 0.912 regarding PP of the left ear and an effect size of 0.946 concerning PP of the right ear. Sample size calculation showed that it would be needed at least 18 children in each group, considering a power $(1-\beta$ err prob) $=0.95$ at a $5 \%$ significance level, estimating a total sample size of 24 children.

We contacted 201 caregivers of children attending seven day-care centres in Porto and 117 agreed to participate in the study (response rate $=58.2 \%$ ). Forty-two children were excluded since they did not meet including criteria (31 had a PRSS $=8$, two children were pre-term births, two had chronic rhinosinusitis, three had crackles in pulmonary auscultation and four children had obstructive ear wax), ending up with a final sample of 75 children. The children were then randomly distributed by a blinded collaborator into an Intervention Group (IG) $(n=37)$ that underwent intervention protocol and a Control Group (CG) $(n=38)$ that continued normal daily 
activities, according to a table of random numbers, between 0 (CG) and 1 (IG), given by the statistical software.

\section{Statistical analysis}

All statistical analyses were carried out using the IBM ${ }^{\circledast}$ SPSS $^{\circledast}$ Statistics 22 software for Windows $8^{\circledR}$, with a confidence interval of $95 \%$ (significance level of $\alpha=0.05$ ).

The descriptive statistical measures used were mean and standard deviation for continuous variables and relative frequency for dichotomous variables.

Inter-group comparisons were analyzed with student's $t$-test for independent samples (continuous variables) and Chi-square test (dichotomous variables). Intra-group comparisons were examined with student's $t$-test for paired samples (continuous variables) and Chi-square test (dichotomous variables).

\section{Results}

\section{Participants}

From the 37 children randomized to IG, 14 were lost to follow-up (6 did not complete the assessment protocol and 8 had corrupted recorded sounds), so the analyzed data refers to the remaining 23 children. Regarding CG, from the 38 children randomly allocated, 17 were lost to follow-up up ( 8 did not complete the assessment protocol and 9 had corrupted recorded sounds), and the reports from the remaining 21 children were analyzed (Fig. 1). Baseline sociodemographic characteristics and risk profile history of children and caregivers from each group are summarized in Table 1, showing that there were no significant differences between both groups.

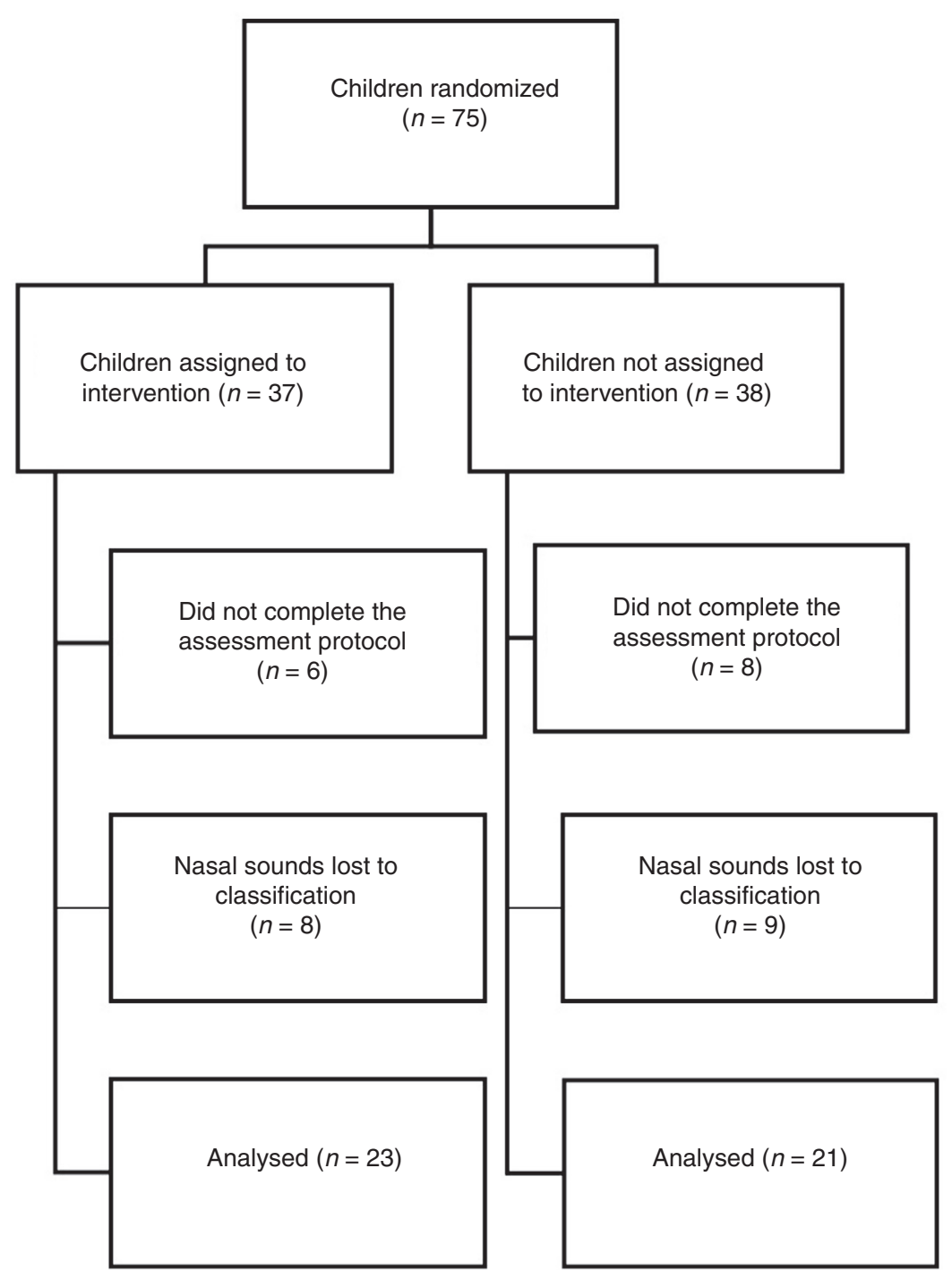

Figure 1 Diagram flow of participants. 
Table 1 Baseline sociodemographic characteristics and risk profile history of children and caregivers from IG and CG.

\begin{tabular}{|c|c|c|c|c|}
\hline & & Control group & Intervention group & $p$ value $(95 \%)$ \\
\hline Caregivers & $\begin{array}{l}\text { Mother's age at child's birth }(X \pm S D) \\
\text { Months of breastfeeding }(X \pm S D) \\
\text { Higher education }(\%)\end{array}$ & $\begin{array}{l}33.8 \pm 4.07 \\
6.14 \pm 3.05 \\
64.7\end{array}$ & $\begin{array}{l}32.3 \pm 4.26 \\
6.56 \pm 4.08 \\
82.6\end{array}$ & $\begin{array}{l}0.278 \\
0.675 \\
0.274\end{array}$ \\
\hline Household & $\begin{array}{l}\text { Household >3 }(\%) \\
\text { Parents' respiratory diseases (\%) } \\
\text { House smoking }(\%)\end{array}$ & $\begin{array}{l}50.0 \\
44.4 \\
27.8\end{array}$ & $\begin{array}{l}34.7 \\
43.5 \\
17.4\end{array}$ & $\begin{array}{l}0.233 \\
1.000 \\
0.471\end{array}$ \\
\hline Children & $\begin{array}{l}\text { Male gender }(\%) \\
\text { Months of age }(X \pm \mathrm{SD}) \\
\text { Weight at birth }(\mathrm{kg})(X \pm \mathrm{SD}) \\
\text { PRSS }(X \pm \mathrm{SD})\end{array}$ & $\begin{array}{r}45.0 \\
20.3 \pm 5.92 \\
3.1 \pm 0.53 \\
9.9 \pm 1.16\end{array}$ & $\begin{array}{r}47.8 \\
22.6 \pm 7.49 \\
3.2 \pm 0.47 \\
10.3 \pm 1.25\end{array}$ & $\begin{array}{l}1.000 \\
0.274 \\
0.968 \\
0.403\end{array}$ \\
\hline Day-care & $\begin{array}{l}\text { Room size }\left(\mathrm{m}^{2}\right)(X \pm \mathrm{SD}) \\
\text { Number of children per room }(X \pm \mathrm{SD})\end{array}$ & $\begin{array}{l}31.9 \pm 7.93 \\
8.07 \pm 2.22\end{array}$ & $\begin{array}{l}28.4 \pm 8.01 \\
9.33 \pm 2.52\end{array}$ & $\begin{array}{l}0.142 \\
0.128\end{array}$ \\
\hline
\end{tabular}

PRSS: Paediatric Respiratory Severity Score.

$X$ : Mean; SD: Standard deviation.

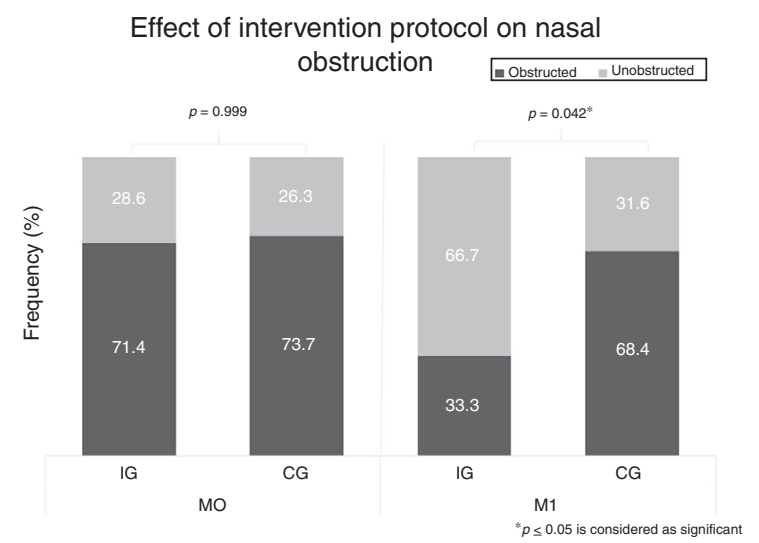

Figure 2 Effect of the rhino-pharyngeal clearance protocol on nasal obstruction of children from in IG and CG.

\section{Results concerning nasal obstruction}

Inter-group comparisons revealed significant differences between groups in $\mathrm{M} 1$, showing that after rhino-pharyngeal clearance there was a higher frequency of children classified as having an unobstructed nasal sound in IG (Fig. 2).

\section{Results concerning the peak pressure of the middle ear}

Concerning the peak pressure (PP) of the middle ear, the results for inter-group comparison did not reveal significant differences between groups. However, intra-group comparison revealed an improvement in the PP of the middle ear, in both ears, immediately after the intervention protocol was completed (M1) which was not verified in CG (Fig. 3).

\section{Results concerning the compliance of the middle ear}

The compliance of the tympanic membrane did not reveal any significant changes with the application of the intervention protocol. The results are summarized in Fig. 4.

\section{Discussion}

This study was the first one that intended to analyze the immediate effect of a rhino-pharyngeal clearance intervention protocol in nasal obstruction, using nasal auscultation. Also, the direct impact of nasal irrigation on children's middle ear it is not well known, thus this study brings original and important evidence.

In fact, there is a lack of proper instruments that can be used in young children in order to assess nasal obstruction. Although acoustic rhinometry, rhinomanometry and peak nasal inspiratory flow are efficient in evaluating the presence of a nasopharyngeal obstruction, their use is restricted, as they are sophisticated and expensive, and consequently are used mainly in laboratory or clinical settings, or else require the patient's cooperation, limiting their use in infants. ${ }^{17}$ Therefore, in order to overcome these difficulties, nasal auscultation was used, since it is a simple and noninvasive procedure and do not requires child's cooperation, besides being calm and quiet. The psychometric characteristics of nasal auscultation were assessed in a prior study, in comparison with other clinical measures. ${ }^{14}$

Indeed, it seems that there are some differences between a nasal obstructed and unobstructed sound, regarding spectral characteristics. Obstructed nasal sounds seem to have a lower frequency and lower intensity than normal nasal sounds, especially in the inspiratory phase. ${ }^{14}$ Still, nasal flow spectral analyses requires consideration of many conditions such as turbulent flow, roughness of the wall, irregular contour of the nasal cavity, collapsible segments, and other resistances as well as the use of appropriate filters that could isolate nasal sound. ${ }^{18}$ 
Effect of intervention on peak pressure of the middle ear

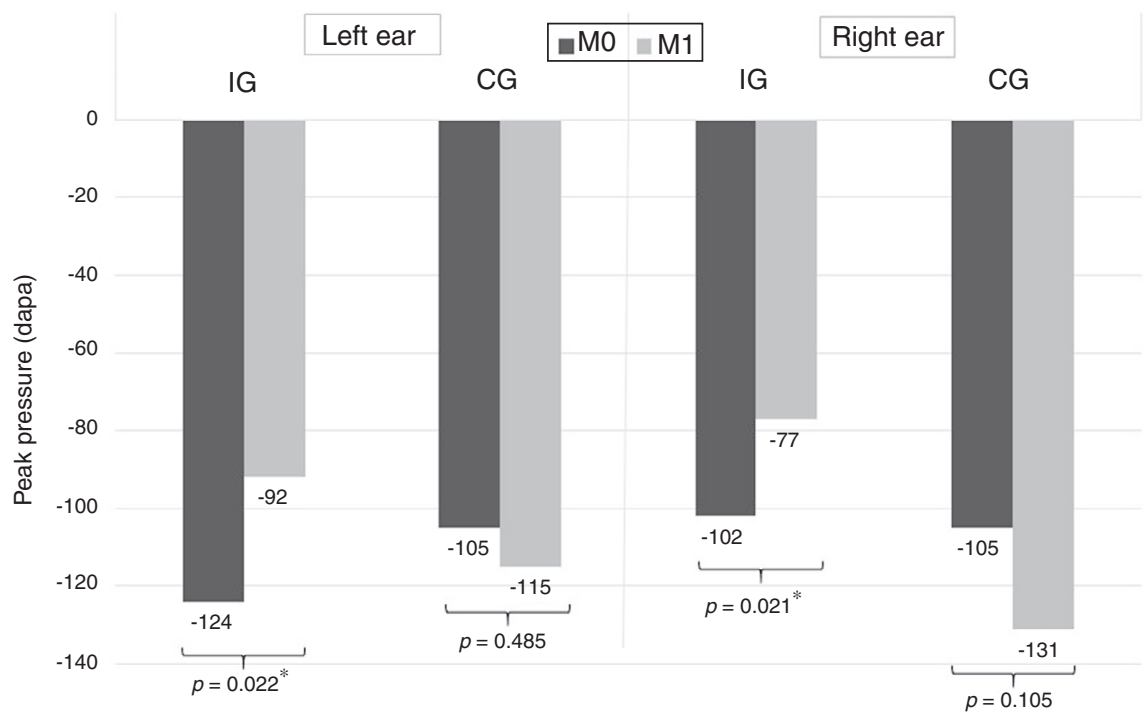

Figure 3 Effect of the rhino-pharyngeal clearance protocol on the Peak Pressure of the middle ear of children from in IG and CG.

Effect of intervention on the compliance of the tympanic membrane

$\square \mathrm{M} 0 \mathrm{M} 1$

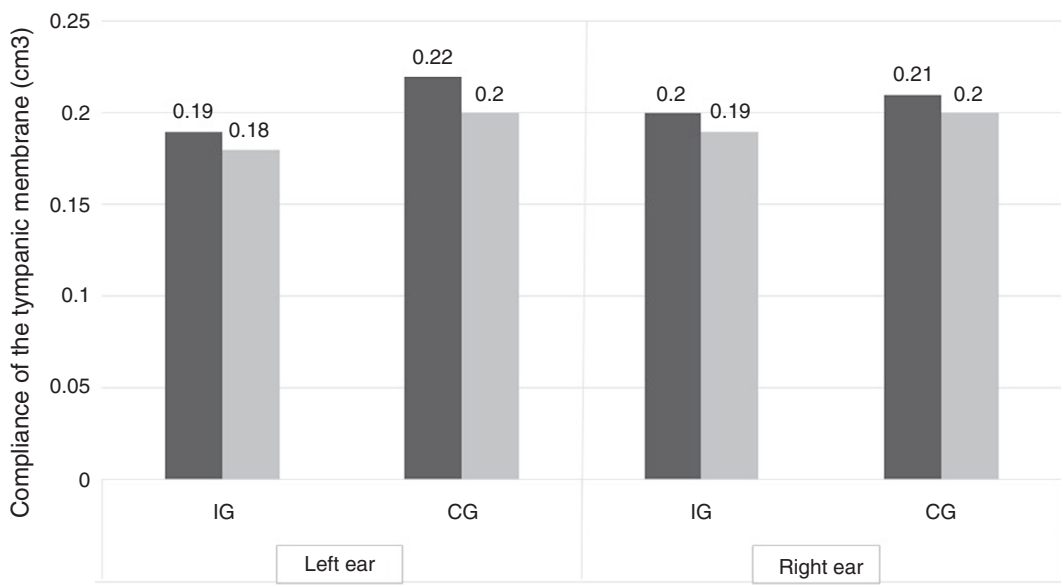

Figure 4 Effect of the rhino-pharyngeal clearance protocol the compliance of the tympanic membrane of children from IG and CG.

This study revealed significant differences between groups, showing a higher frequency of children classified as having an unobstructed nasal sound after rhino-pharyngeal clearance, in comparison to control group.

There is a lack of research about nasal auscultation and only a few studies about pulmonary auscultation, which is considered to be a less precise assessment in children than in adults, since its reliability have been classified as poor to moderate. ${ }^{19}$ However, in a previous study it was found a substantial inter-rater reliability and a good intrarater reliability for nasal auscultation in children under 3 years of age. ${ }^{14}$ Nevertheless, this substantial agreement of measurements, whether between examiners and within the same examiner, proves only that there is a significant consistency in the classification of nasal sounds and do not predict the accuracy of their classification. Therefore, the effect of the rhino-pharyngeal clearance protocol in the middle ear condition of children with URTI was also analyzed, taking into account the relation between the obstruction of the nasopharynx and the Eustachian tube dysfunction. $9,10,20$

It is well stated that URTI often leads to an inflammation of the nasopharynx, causing obstruction of the Eustachian Tube, creating a negative pressure inside the middle ear, which results in effusion and aspiration of 
nasopharyngeal secretions. ${ }^{21-23}$ This alters the condition of the middle ear, predisposing to Acute Otitis Media (AOM). 20,21,23

A prior study found an important relationship between the nasal sounds classification by the experts and the values of peak pressure of the middle ear of young children. ${ }^{14}$ They verified that children classified with "non-obstructed" nasal sounds revealed higher PP values than those classified as "obstructed,"'. So, maybe the removal of the secretions from the nasopharynx, could restore the pressure of the middle ear, normalizing the function of the Eustachian Tube.

Our results showed that the children who were submitted to the rhino-pharingeal clearance protocol had an immediate improvement of the peak pressure (PP) of the middle ear, which was not verified in CG. It is known that there is an association between negative pressure of the middle ear and nasopharyngeal obstruction, as well as rhinorrhea. ${ }^{24,25}$ So, an improvement in PP immediately after intervention protocol could mean that it was successful in reducing or eliminating nasal secretions, reestablishing nasal breathing and promoting the ventilation and drainage of the middle ear. ${ }^{7-10}$ Furthermore, children who have low PP values during URTI and take more time to recover to a normal $\mathrm{PP}$, have an increased risk of Otitis Media with Effusion and AOM, so, a successful improvement in PP values may also decrease the risk of AOM. ${ }^{26}$

Although nasal irrigation has a positive effect on nasal congestion of children with URTI, being able to clear germs, allergens and other pollutants from the nasopharynx and reducing the use of medications, , 5,11,27,28 it seems to have only a minor effect on the posterior region of the nasal cavities. ${ }^{29}$ So, the addition of Désobstruction Rhinopharyngée Rétrograde manoeuvre ensures the clearance of the posterior region of nasal cavities (cavum), which is the proximal end of Eustachian tube, thus helping normalizing PP of the middle ear. ${ }^{15}$ Intervention studies are needed to provide more consistent data on the effectiveness of this manoeuvre in infants, however, the clinical results are immediate and sometimes impressive. ${ }^{15}$

In this study, the compliance of the tympanic membrane did not reveal any significant changes immediately after the intervention protocol. This can be due to the fact that the mobility of the tympanic membrane is related with the inflammatory process of the nasopharynx, causing oedema, which decreases its mobility even if PP is no longer abnormal. ${ }^{30}$ This means that it would be needed more interventions and/or a larger follow-up in order to know if compliance would achieve normal values, which is a limitation of this study. Another limitation was the lack of a gold standard instrument that could be used in a community setting to measure nasal obstruction in infants limits the validation of the intervention protocol.

Further studies are needed with larger samples, more days of intervention and longer follow-ups in order to verify if the changes in PP could be maintained over time and if occurs any improvement in the compliance of the tympanic membrane. It would be also interesting to analyze the clinical effects of the Rhino-pharyngeal clearance protocol in the frequency of OME or AOM.

\section{Conclusions}

The rhino-pharyngeal clearance protocol has immediately improved the nasal obstruction and the PP of the middle ear of children under 3 years of age with URTI, attending day-care centres in Porto.

\section{Declarations}

Ethical approval was obtained from the Ethics Committee of the School of Allied Health Technologies, Polytechnic Institute of Porto (CE_1744/2014).

This study is registered at ClinicalTrials.gov with the identifier: NCT02588963.

\section{Acknowledgements}

The authors would like to thank all of the children, caregivers and childcare workers who participated in this study. We also thank Professor Paula Lopes, Head of the Department of Audiology, for the support showed during the research work and Natália Oliveira for her collaboration in the tympanometric assessment. A special thanks to Daniel Costa and Ana Alves for their collaboration in pilot-testing and to Andreia Noites for her availability and statistical advices.

\section{References}

1. Stover CS, Litwin CM. The epidemiology of upper respiratory infections at a tertiary care center: prevalence, seasonality, and clinical symptoms. J Respir Med. 2014;2014:1-8.

2. Serra ME. Prevention of respiratory infections at day care centers: recommendations and systematic review of the evidence. Arch Argent Pediatr. 2014;112:323-31.

3. Kusel MM, De Klerk N, Holt PG, Landau LI, Sly PD. Occurrence and management of acute respiratory illnesses in early childhood. J Paediatr Child Health. 2007;43:139-46.

4. Mitra A, Hannay D, Kapur A, Baxter G. The natural history of acute upper respiratory tract infections in children. Prim Health Care Res Dev. 2011;12:329-34.

5. Chirico G, Quartarone G, Mallefet P. Nasal congestion in infants and children: a literature review on efficacy and safety of nonpharmacological treatments. Minerva Pediatr. 2014;66:549-57.

6. Simasek M, Blandino DA. Treatment of the common cold. Am Fam Phys. 2007;75:515-20.

7. Marchisio P, Picca M, Torretta S, Baggi E, Pasinato A, Bianchini $S$, et al. Nasal saline irrigation in preschool children: a survey of attitudes and prescribing habits of primary care pediatricians working in northern Italy. Ital J Pediatr. 2014;40:1-8.

8. Postiaux G, Souza Pinto V, Vieira DR, Carvalho CM. Fisioterapia respiratória pediátrica: o tratamento guiado por ausculta pulmonar. Porto Alegre: Artmed Editora; 2004. 
9. Dhooge IJ. Risk factors for the development of otitis media. Curr Allergy Asthma Rep. 2003;3:321-5.

10. Heikkinen T, Chonmaitree T. Importance of respiratory viruses in acute otitis media. Clin Microbiol Rev. 2003;16:230-41.

11. Wang YH, Yang CP, Ku MS, Sun HL, Lue KH. Efficacy of nasal irrigation in the treatment of acute sinusitis in children. Int J Pediatr Otorhinolaryngol. 2009;73:1696-701.

12. Šlapak I, Skoupá J, Strnad P, Horník P. Efficacy of isotonic nasal wash (seawater) in the treatment and prevention of rhinitis in children. Arch Otolaryngol Head Neck Surg. 2008;134: 67-74.

13. Alexandrino AS, Santos R, Melo C, Bastos J, Postiaux G. Subjective and objective parameters in paediatric respiratory conditions: cultural adaptation to Portuguese population. Fisioter Mov. 2017;30:49-58.

14. Santos R, Silva A, Tomé D, Melo C, Mesquita A, Costa D, et al. Inter-and intra-rater reliability of nasal auscultation in daycare children. Minerva Pediatr. 2018;70:20-6.

15. Postiaux G. Quelles sont les techniques de désencombrement bronchique et des voies aériennes supérieures adaptées chez le nourrisson? Arch Pediatr. 2001;8:117-25.

16. Gomes ÉL, Postiaux G, Medeiros DR, Monteiro KK, Sampaio LM, Costa D. Chest physical therapy is effective in reducing the clinical score in bronchiolitis: randomized controlled trial. Braz J Phys Ther. 2012;16:241-7.

17. Van Spronsen E, Ingels K, Jansen A, Graamans K, Fokkens W. Evidence-based recommendations regarding the differential diagnosis and assessment of nasal congestion: using the new GRADE system. Allergy. 2008;63:820-33.

18. Tahamiler R, Canakcioglu S. Evaluation of nasal obstruction with Odiosoft-Rhino in nasal septal deviation. J Otolaryngol Head Neck Surg. 2008:37.

19. Elphick H, Lancaster G, Solis A, Majumdar A, Gupta R, Smyth R. Validity and reliability of acoustic analysis of respiratory sounds in infants. Arch Dis Child. 2004;89:1059-63.
20. Chonmaitree T, Trujillo R, Jennings K, Alvarez-Fernandez P, Patel JA, Loeffelholz MJ, et al. Acute otitis media and other complications of viral respiratory infection. Pediatrics. 2016, e20153555.

21. Nokso-Koivisto J, Hovi T, Pitkäranta A. Viral upper respiratory tract infections in young children with emphasis on acute otitis media. Int J Pediatr Otorhinolaryngol. 2006;70:1333-42.

22. Corbeel L. What is new in otitis media? Eur J Pediatr. 2007;166:511-9.

23. Chonmaitree T, Alvarez-Fernandez P, Jennings K, Trujillo R, Marom T, Loeffelholz MJ, et al. Symptomatic and asymptomatic respiratory viral infections in the first year of life: association with acute otitis media development. Clin Infect Dis. 2014;60:1-9.

24. Tomé D, Alexandrino AS, Santos R, Melo C, Costa D, Ferreira JP. Characterization of middle-ear condition of Oporto daycare children up-to 3 years-old: a cross sectional study. Int J Pediatr Otorhinolaryngol. 2014;78:2132-5.

25. Palmu AA, Syrjänen R. Diagnostic value of tympanometry using subject-specific normative values. Int J Pediatr Otorhinolaryngol. 2005;69:965-71.

26. Winther B, Hayden FG, Arruda E, Dutkowski R, Ward P, Hendley JO. Viral respiratory infection in schoolchildren: effects on middle ear pressure. Pediatrics. 2002;109:826-32.

27. Rabago D, Zgierska A. Saline nasal irrigation for upper respiratory conditions. Am Fam Phys. 2009;80:1117-9.

28. Shaikh N, Wald ER. Decongestants, antihistamines and nasal irrigation for acute sinusitis in children. Cochrane Database Syst Rev. 2014:10.

29. Wormald PJ, Cain T, Oates L, Hawke L, Wong I. A comparative study of three methods of nasal irrigation. Laryngoscope. 2004;114:2224-7.

30. Bluestone CD, Klein JO. Physiology, pathophysiology, and pathogenesis. In: Otitis media in infants and children. 4th ed. PMPH-USA; 2007. p. 41-72. 